\title{
Yeme Eylemi; Fizyolojik Bir İhtiyaç mı? Psikolojik Bir Davranış mı? Üniversite Öğrencilerinde Bağlanma Stilleri ile Yeme Bağımlılı̆̆ı İlişkisi
}

\author{
Emine $\mathrm{AKTEN}^{1}$, Cemal Onur NOYAN ${ }^{2}$
}

\begin{abstract}
Özet: Bağlanma stilleri, bireyin gelişim evrelerinin tamamlamasının belirleyicilerindendir. Sağlam temellerde, bireyde güven duygusunu geliştirirken, tersi durumda yaşam tarzını, sosyal ilişkilerini, davranışlarını, ekonomik tavrını, iş ve insanlar ile ilgili ilişkisini olumsuz etkileyen duygusal etkiler yaratır. Bu nedenle bağlanma stilleri fizyolojik ihtiyaçtan kaynaklansa da psikolojik etkenlerle birleşerek kişilerin yeme davranışlarını da belirlemektedir. Bu amaçla, 150 üniversite öğrencisi ile bu çalışma yapılmıştır. Araştırmada, Sosyodemografik form, Yale Yeme Bağımlılık Ölçeği ile İlişki Ölçekleri Anketi kullanılmıştır. Yeme bağımlılı̆̆ kriterlerini karşılayan öğrencilerde bağlanma stilleri tespit edilerek ilintili yeme davranış örüntüleri belirlenmiş, tümünün yeme bağımlılı̆̆ına etkisi araştırılmıştır. Bağlanma stillerinin kişilerde yeme tutumlarını etkilediği, cinsiyetin tutumu değiştirdiği, bağımlılı̆ı̆ı en temel belirleyicisi olan olumsuz sonuçları bilinmesine rağmen yeme davranışları devam edildiği bu çalışma ile tespit edilmiştir.
\end{abstract}

Anahtar Kelimeler: Bağımlılık, Yeme Bağımlılı̆ı̆, Bağlanma Stilleri, Psikolojik Dayanıklılık

Eating Action; A Physiological Need or a Psychological Behavior?

\section{The Relationship Between Attachment Styles and Food Addictions in University Students}

\begin{abstract}
Abastact: Attacment styles are the determinants of the completion of the individual's developmenttal stages. On solid foundations, while developing the of development, sense of trust in the indivudual, he creates his life, social relations, behaviors, economic attitude and the relations between work and people in the opposite environment by emotionally emotionalizing. This is due to psychological factors and psychological factor. İn this year 150 universty students in this field with resarch. Sociodemographic form, Yale Eating Dependence Scala and Relationship Scales questionnaire. Correlated eating behavior patterns werw adjusted and all of them were analyzed for eating dependence. Although attacment styles affect past attitudes, gender changes attitudesand negative thoughts which are the most important determinants of addiction are planned to work in this area which continues eating behaviors.
\end{abstract}

Key words: Addiction, Food Addiction, Attacment Styles Psychological Endurance

\author{
${ }^{1}$ Psk., Üsküdar Üniversitesi, İstanbul \\ ${ }^{2}$ Doç. Dr., Üsküdar Üniversitesi, İstanbul \\ Address of correspondence/ Yazışma adresi: Psk. Emine Akten, Üsküdar Üniversitesi, İstanbul, E-mail: \\ emineakten1@hotmail.com
}

Date of Received/Geliş Tarihi: 19.10.2019, Date of Revision/Düzeltme Tarihi: 02.11.2019, Date of Acceptance/Kabul Tarihi: 06.11.2019

Citing/ Referans Gösterimi: Akten, E., Noyan, C.O. (2019). Yeme Eylemi; Fizyolojik Bir İhtiyaç mı? Psikolojik Bir Davranış mı? Üniversite Öğrencilerinde Bağlanma Stilleri ile Yeme Bağımlılı̆̆ı İlişkisi. Kıbrıs Türk Psikiyatri ve Psikoloji Dergisi, 1(Özel Sayl.1): 30-32 doi:10.35365/ctjpp.19.special1.8 


\section{Giriş}

Bağlanma stillerini, yetişkinlerde görülebilecek bağımlılıklar başta olmak üzere tüm olumlu-olumsuz davranışların belirleyicisi olarak görmek mümkündür. Davranış bağımlılıkları, madde bağımlılığına kıyasla daha düşük fiziksel risk oluşturmasına karşın, türü ne olursa olsun kişilerde psikolojik, nörolojik ve sosyolojik problemler yaratır. Davranıșsal bağımlılıklarda, tutum yada faaliyeti kontrol edememe, negatif neticelere karşın tutuma devam etme ve bu tutumun devamlılık göstermesi temel belirleyicilerdi. Davranış bağımlılığı türü olan yeme bağımlılığı; bağımlılık yaratabilecek olan gıdalardan özellikle tatlı, çikolata, şekerleme ve karbonhidrattan zengin besinlere karşı fazla arzu hissetme olarak tanımlanmaktadır.(Mıchener, 1994) Çikolata gibi tatlı bir gıdaların tüketiminin ölçülebilir bir psikoaktif etkisinin olduğu, çikolatanın içersindeki kakao ve şekerin de aşermede en etkili madde olduğunu saptamıştır. Yeme bağımlılığı, bağımlılık davranışı ile paralellik gösterir. $\mathrm{Bu}$ paralellik haz arayışının olgusu ve kontrol kaybının oluşudur(Nasser, 2019) Yeme bağımlılı̆̆ kavram olarak, obezitede olan yeme türünün tümünü açıklamaya yetmez. Ancak bağımlılıkta ortaya çıkan birçok nörobiyolojik değişikler, obezlerdede yüksek oranda saptanmıştır(Devlin M., 2007).

\section{Yöntem}

Araştırma evrenini, Üsküdar Üniversitesinde eğitim (2018-2019) gören 18-25 yaş arası 80 kadın ve 70 erkek öğrenci oluşturmakta olup, Sosyodemografik Bilgi Formu, Yale Yeme Bağımlılık Ölçeği (YBÖ) ve İlişki Ölçekleri Anketi (İÖA) araştırmanın ölçüm araçlarını oluşturmaktadır. Değerlendirmede, tanımlayıcı ve yüzdelik hesaplama, varyans analizi, bağımsız grup karşılaştırılmasında independent $t$ test kullanılmıştır.

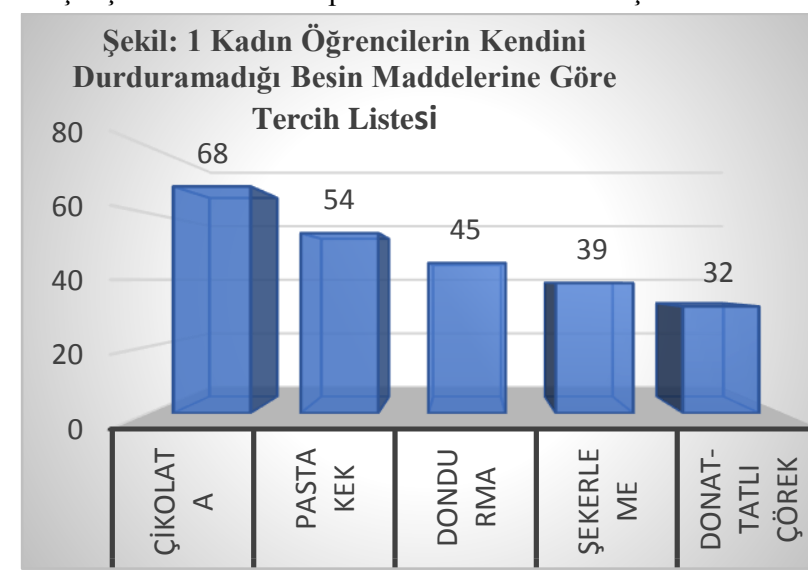

\section{Tartışma ve Sonuç}

Çalışmamızın en önemli sonucu, tanı kriterlerini karşılayan kadın ve erkek ögrencilerde cinsiyet açısından anlamlı farklılık oluşturmazken, katılan tüm öğrencilerde yeme bağımlılı̆̆ $\% 28$ olarak tespit edilmiştir. Literatürlerde yeme bağımlılığ $; \% 11, \% 24$ (Murphy ve ark., 2014), \%17,24 (Kayhan ve ark., 2016), \%11,4 ((Kıcali F., 2015)), \%21,7 (2017)'dir. Yeme davranış1, fizyolojik bir ihtiyaçtan çok haz odaklı bir davranış haline geldiğinde, obezite başta olmak üzere birçok hastalık ile seyreden bir yaşam şekline dönüşebilmektedir. YBÖ'ne verilen yanitlara göre yapılan analiz sonucunda kriter karşılama oranları içinde en yüksek $\% 89,33$, ile

\section{Bulgular}

Katılımcıların, \%53.3'ünün $(\mathrm{n}=80)$ kadınlardan ve \%46.7'sinin $(\mathrm{n}=70)$ erkeklerden oluştuğu, \% 92,7'sinin $(\mathrm{n}=139)$ bekar, \% 52.7'sinin $(\mathrm{n}=79)$ gün içerisinde düzenli beslenmediği, \% 82.0'sinin $(n=123)$ öğün diş1 beslendiği, \% 32.0'ının $(\mathrm{n}=48)$ yemekte kendini durduramadığı, madde kullanım durumları açısından ise \% 26.0'sinın ( $\mathrm{n}=39)$ sigara kullandı $\breve{1} 1, \%$ 8.0'inin $(\mathrm{n}=12)$ alkol kullandığ $1 \% 66.0$ ' $\sin ı n(n=99)$ ise sigara, alkol ve madde kullanmadığı saptanmıştır. Yale Yeme bağımlılığ ölçeği değerlendirilmesinde; yeme bağımlılığı kriterlerini karşılanma oranı kadın ve erkek öğrenciler için \%28 $(n=42)$ olarak bulunmuştur. YBÖ $(+)$ ve $(-)$ ögrencilerde İÖA değerlendirilmiştir. Bağlanma stillerinden "Güvenli" $(\mathrm{r}=.23, \mathrm{p}=.04)$, "Korkulu" $(\mathrm{r}=.18, \mathrm{p}=.02)$ ve "Saplantılı" bağlanma arasında pozitif yönde anlamlı bir iliş̧ki bulunmuştur (Şekil 1-2). Katılımcılara, YBÖ soruları için yapılan frekans analizinde en yüksek değer "Olumsuz sonuçların bilinmesine rağmen yemeye devam etme" alt boyutunun \%89,33 oranında karșılandığı görülmüştür. Kriter karşılama durumu \%24,67 ile en düşük "Azalan veya vazgeçilen sosyal hayat, iş ve boş zaman aktivitesi," olmuştur. Katılımcılar YBÖ 25.inci sorusunda; "kendilerinde aşırı yeme isteği uyandiran ve yerken kendini durduramadikları yiyecek türleri'ni cevaplamıştır. Buna göre; kadın ve erkeklerde birinci tercih besini \%45,33 ile "çikolata", ikinci \%36,67 ile "dondurma", üçüncü \%32,67 ile pasta-kek, dördüncü \%26 ile "ş̧ekerleme" olmuştur. Kadın öğrencilerin $\% 67,5$ 'i "çikolata" diyerek "tatlı" besinleri, erkek ögrencilerin \%35,71'i "pizza-lahmacun" diyerek "tuzlu ve hamurlu" besinleri tercih etmiştir. Yale Bağımlılık Ölçek puanları yüksek kadın öğrencilerin \%87'si, erkek ögrencilerin \% 65'i "5 ve üzeri” çeşit besin maddesinde kendini durduramadığını belirtmiştir (Şekil 1-2)

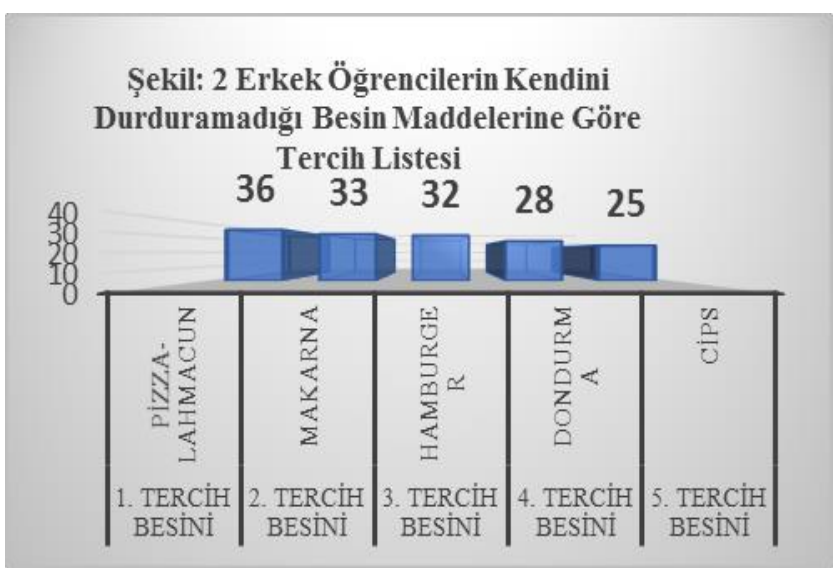

"olumsuz sonuçların bilinmesine rağmen yemeye devam etme” kriteri olmuştur. Kıcali'nın (2015) çalışmasında da aynı kriter \% 67.6 gibi bir değer alırken, Kayhan M. Ve A.Ünveren'nin ( 2017) çalışmasında \%87,7 olmuştur. Bu sonuçlar ile bağımlılık kavramında önemli bir unsur olan "zararları bilinmesine rağmen bağımlılık yaratan nedeni terk edememe" durumu bu çalışmada da saptanmıştır. Öğrencilerde hangi besin öğelerinin daha zararlı olabileceğine dair bilgi, tecrübe ve farkındalıklarının daha yüksek olabilmesi beklenmektedir ancak gerçekte durumun böyle olmadığına işaret etmesi açısından da bu bulgu önemlidir. Araştırmamıza katılanlara YBÖ'nin 26.sorusunda, "aşırı yeme isteği uyandıran, kendini durduramadıkları besin maddelerini" işaretlemeleri 
istenmiştir. $\mathrm{Bu}$ besinler, peynir, et, meyve, karnabahar gibi besin maddelerinin yanında, kola, gazoz, cips, şekerleme, hamburger, et, makarna, ekmek, pizza, çikolata, pasta kraker, bisküvi vb gibi 30 değişik besin maddesini içermektedir. Katılımcıların \%95'i hazır, haz uyandıran, lezzetli, şekerli, hamurlu, yemesi ve erişimi kolay besin maddelerinde kendilerini durduramadıklarını belirtirken hiçbiri sebze seçeneğini işaretlememiştir. Kadın öğrencilerin çoğu "tatlı" erkek öğrencilerin ise "tuzlu, hamurlu" besin tercih etmesi cinsiyet değişkeni açısından fark yaratmıştır. Kayhan M. Ve A.Ünveren'nin (2017) çalışmasında, ilk sırada \%44.9 ile Çikolata/Gofret, ikinci sırada \%32.6 ile Kola/Gazoz, üçüncü sırada \%28.7 ile cips, dördüncü sırada \%27.4 ile ekmek ve beşinci sirada \%26.9 ile Pizza/Lahmacun/Döner, Dayılar'ın H.'ın (2015) ((Dayılar H., 2015)) çalışmasında da ilk tercih besini \%46.9 ile Çikolata/Gofret, ikinci \%44.6 ile cips, üçüncü \%42 ile kola ve dördüncü \%39.9 ile Pizza/Lahmacun/Döner olarak belirtilmiştir. Yeme bağımlılığ yaratan «tatlı, şekerli, kakaolu» yiyecekler bu araştırmada da «aşırı yeme istediği oluşturan, kendini durduramadıkları» besin grubunu oluşturmuştur. Bağlanma açısından ise, güvenli bağlanan kişilerin kendini sevdiği, olumlu benlik algısına sahip, özgüven ve öz-yeterliliği yüksek, kişiler arası ilişkileri güvene dayalı ve güçlü olduğu, bunun tam aksine saplantılı ve korkulu bağlanan kişilerin olumsuz benlik algısına sahip, değersizlik duygusu içinde yaşadıkları, ilişkilerinde zorlayıcı ve bıktırıcı oldukları, bağımlı kişilik özellikler sergiledikleri bilinmektedir. Araştırmamızda, YBÖ puanları ile "saplantılı", "korkulu", "güvenli" bağlananlarda pozitif yönde anlamlı bir ilişki çıkması, bağlanma stillerinin kişilerin bağımlılık davranışlarını belirlemesi açısından önemli bulunmuştur.

Sonuç olarak, üniversite öğrencileri için temel sorun beslenme düzenidir. Düzensiz ve hızlı yeme, tercih edilen besin maddelerinin haz uyandıran şekerli gıdalar olması, sağlıksız ve fazla miktarda tüketilmesi bir süre sonra yeme bağımlılığına ve obeziteye dönüşebilecektir. Aile içi yakın ve paylaşımlı ilişkilerin yeme tutumlarını etkilediği bilinmektedir. Çalışmamız bulgularından hareketle, sıcak aile iletişimimin kişiliği olumlu etkilediği, yemek tüketiminde, sağlıklı beslenme alışkanlıkları kazandırmasında etkili olduğu, bireyleri zararlı alışkanlıklardan uzaklaştırarak daha sağlıklı birey ve toplum oluşmaya katkıda bulunacağı unutulmamalıdır.

\section{Kaynaklar}

Dayılar H. (2015). Lise Öğrencilerinde Yeme Bağımlllı̆̆g ve Etkileyen Faktörler, Yüksek Lisans Tezi. İstanbul Üniversitesi, Yüksek Lisans Tezi . İstanbul.

Devlin M. (2007). Work Group on Eating Disorder, Guideline for the Treatment Of Patiens With Eating Disorder. Washington DC.
Kıcali F. (2015). Üniversite Öğrencilerinde Beslenme Alışkanlıkları ve Yeme Bağımlılığına Farklı K. Selçuk Üniversitesi Tıp Fakültesi, Uzmanlık Tezi . Konya.

Michener, W. R. (1994). Pharmacological versus sensory factors in the staiation of chocolate craving: Physicol Behavior.

Nasser, J. A. (2019). Increasing Chocolate's Sugar Content Enhances Its. 